\title{
The role of nutrition in the treatment of irritable bowel syndrome
}

\author{
ANTOINE AOUN ${ }^{1, A, B, D-F}$, JESSICA MAALOUF², B, D-F, \\ ORCID ID: 0000-0001-9108-733X \\ SARA KHALIL 2, B, D-F, VERONIQUE EL KHOURY², B, D-F
${ }^{1}$ Medical Center and Department of Nursing and Health Sciences, Notre Dame University-Louaize, Zouk Mosbeh, Lebanon
${ }^{2}$ Department of Nursing and Health Sciences, Notre Dame University-Louaize, Zouk Mosbeh, Lebanon

A - Study Design, B - Data Collection, C - Statistical Analysis, D - Data Interpretation, E - Manuscript Preparation, F - Literature Search, $\mathbf{G}-$ Funds Collection

\begin{abstract}
Summary Background. The prevalence of functional bowel disorders is on the rise worldwide. Irritable bowel syndrome (IBS) is a chronic functional gastrointestinal disorder characterized mainly by abdominal cramps, flatulence, and abnormal bowel movements. Due to the lack of specific biomarkers and of a specific diagnostic test, IBS is diagnosed according to the Rome IV clinical criteria. The current holistic approach recommends dietary management as the initial therapy for IBS patients with mild and moderate symptoms. Objectives. This review examines the studies on the effect of various types of diets on IBS as well as on the primary dietary therapy in IBS patients.

Material and methods. A literature review of published studies was conducted by searching the Medline-PubMed database using the MeSH (Medical Subject Headings) descriptor and the following keyword combinations: "irritable bowel syndrome" and "treatment" ( $n=11$ articles), "irritable bowel syndrome" and "diet or nutrition" ( $n=26$ articles), "irritable bowel syndrome" ( $n=9$ articles), and "gluten", "irritable bowel syndrome" and "lactose" ( $n=4$ articles).

Results. Contradictory results were found in many studies regarding several diets such as diet excluding gas-producing foods, diet low in lactose, gluten-free diet, diet low in fermentable oligosaccharides, disaccharides, monosaccharides and polyols (FODMAP) and the role of fiber, alcohol, caffeine, and natural remedies and their applications in different IBS subtypes.

Conclusions. Short-term restriction of FODMAP may be the most effective dietary intervention for reducing IBS symptoms compared to other types of diet.

Key words: diet, glutens, irritable bowel syndrome, lactose.
\end{abstract}

Aoun A, Maalouf J, Khalil S, El Khoury V. The role of nutrition in the treatment of irritable bowel syndrome. Fam Med Prim Care Rev 2021; 23(4): 495-500, doi: https://doi.org/10.5114/fmpcr.2021.108206.

\section{Background}

The prevalence of functional bowel disorders (FBD) is on the rise worldwide. These disorders are known for their ability to affect all members of our society [1]. Irritable bowel syndrome (IBS) is a chronic, relapsing and lifelong FBD characterized by abdominal pain or cramps, alternating bowel habits, excess gas, bloating, heartburn, and dyspeptic symptoms that vary from one individual to another [2]. The global prevalence of IBS is estimated to be between $10 \%$ to $20 \%$ with higher prevalence in females, individuals under 50 years old, and those with a family member diagnosed with IBS [3-7]. Due to the lack of symptoms such as biomarkers and physiological abnormalities, IBS is diagnosed by clinical criteria [5, 8]. According to Rome IV, IBS is diagnosed by recurrent abdominal pain at least one day a week in the last three months, and associated with two or more of the following criteria: related to defecation, associated with a change in stool frequency, and associated with a change in stool appearance. Individuals who meet the IBS diagnostic criteria should undergo the following tests to rule out other inflammatory diagnoses: antibody testing for celiac disease, erythrocyte sedimentation rate (ESR), cell blood count (CBC) and c-reactive protein (CRP) [9]. Various IBS subtypes are defined according to patients' predominant bowel habits on days with abnormal bowel movements, using the Bristol stool form scale (BSFS) $[10,11]$. BSFS categorizes stool consistency into one of seven types ranging from type 1 (hard) to type 7 (watery diarrhea) (Table 1) [10]. The three main IBS subtypes include IBS with predominant constipation (IBS-C), IBS with predominant diarrhea (IBS-D), and IBS with mixed bowel habits (IBS-M). Individuals whose bowel habits cannot be grouped into one of those three categories are considered to have unclassified IBS (IBS-U).

Table 1. IBS subtypes classified based on abnormal bowel movements according to Rome IV; Bowel movements (BM)

\begin{tabular}{|l|l|l|}
\hline IBS Subtype & $\begin{array}{l}\text { Stool Type (1 and 2) } \\
\text { Hard stools }\end{array}$ & $\begin{array}{l}\text { Stool Type (6 and 7) } \\
\text { Watery diarrhea }\end{array}$ \\
\hline IBS-C & More than 25\% of BM & Less than 25\% of BM \\
\hline IBS-D & Less than 25\% of BM & More than $25 \%$ of BM \\
\hline IBS-M & More than 25\% of BM & More than 25\% of BM \\
\hline
\end{tabular}

\section{The role of diet}

The recommended approach for IBS therapy relies on an individualized management based on lifestyle and dietary interventions as well as medical and psychosocial treatments [3]. More importantly, the therapies should be tailored to the subtype of IBS diagnosed as well as the main exhibited symptoms [12], in addition to behavioral interventions to reduce co-mor- 
bid stress and anxiety [13]. The traditional first-line therapy included over-the-counter medications for diarrhea (loperamide and probiotics) and constipation (laxatives and fiber pills). In spite of their low-cost and wide availability, these drugs have no effect on recurrent abdominal symptoms [3]. The current holistic approach (since 2000s) recommends dietary management as the initial therapy for IBS patients with intermittent and mild symptoms [14]. Pharmacotherapy - in the form of medications for motility control, visceral hypersensitivity, and pain - is only recommended for patients with IBS-impaired quality of life or those with moderate to severe symptoms as ancillary to the dietary intervention $[11,13]$. The basic dietary advice for IBS, developed by the National Institute for Health and Care Excellence (NICE) clinical practice guidelines (2008) [9], cites the importance of regular meals with plenty of fluids (at least eight cups), reducing alcohol intake, cutting down on caffeine in coffee and tea, eating high-fiber foods and resistant starch, in addition to avoiding sorbitol in IBS-D and a controlled intake of a maximum of three portions of fruit per day. Some beneficial dietary components are said to be oats, linseeds as well as soluble fiber and prebiotics. The data on the role of diet in the onset of IBS-symptoms and pathophysiology is still limited, but some possible mechanisms include intolerance and hypersensitivity or interactions with the gut microbiota and hormones [15, 16]. According to Ford et al. [12], specialized diets may improve symptoms in IBS patients. The quality of evidence remains very low with a weak recommendation level. A dietitian-led detailed diet history and symptom record helps in finding through trial and error specific food triggers to adopt the best dietary strategy, such as avoiding gas-producing foods or following a high-fiber diet, a lactose-free, or gluten-free diet, or a diet low in fermentable oligosaccharides, disaccharides, monosaccharides, and polyols (FODMAP) [11]. This review serves to examine the latest research on the effect of the diets mentioned above on IBS as well as the primary dietary therapy in IBS patients.

\section{Material and methods}

A literature review of published studies mostly ranging from January 2015 till December 2020 was conducted by searching the scientific MEDLINE-PubMed database using the MeSH (Medical Subject Headings) descriptor. The keyword combinations used were "irritable bowel syndrome" ( $n=11$ articles), "irritable bowel syndrome" and "diet" ( $n=26$ articles), "irritable bowel syndrome" ( $n=9$ articles), and "gluten", "irritable bowel syndrome" and "lactose" ( $n=4$ articles). The search yielded a total of 50 articles excluding animal studies. Of the 50 articles, 30 were literature reviews, ten were randomized clinical trials (RCTs), four were meta-analyses, four were observational studies and two were clinical practice dietary guidelines. The above steps are shown in Figure 1.

Figure 1. Stages of study selection and inclusion of articles

\section{Results and discussion}

\section{Diet low in gas-producing foods}

The exclusion diet based on avoidance of foods that produce intestinal gas is advised and applicable to all subtypes of IBS. The main mechanism that creates the discomfort following ingestion of gas-producing foods is linked to increased visceral hypersensitivity in IBS patients [11], since these foods accompany bacterial fermentation that leads to bloating and flatulence [12]. It was found that IBS symptoms are a cause of hypersensitivity to distention rather than an excess production of gas [17]. The colonic fermentation of undigested substrates yields short-chain fatty acids and gas products, mainly carbon dioxide, hydrogen and methane [18]. The types of foods to be avoided are presented in Table 2 and based on Wald [11]. Other foods to steer clear of include resistant starch found in some breads, products with modified starch and cold/re-heated potatoes [9]. In case of lingering symptoms after this diet, a trial of lactosefree diet is advised [11, 13].

\section{Table 2. List of gas-producing food items to be avoided in IBS} patients

\section{Gas-producing food items}

Pretzels, alcohol, bagels, bananas, apricots, beans, caffeine, celery, onions, carrots, prunes, raisins, wheat germ, Brussel sprouts

\section{Diet low in lactose-containing foods}

Lactose intolerance develops because of genetic or acquired lactase deficiency where the gas by-products of colonic bacterial fermentation of lactose lead to nausea, diarrhea, bloating and pain [18]. A prevalence of $10 \%$ lactose intolerance was described among IBS patients [9]. Among patients with IBS-D, lactose intolerance is higher than in healthy controls. Moreover, the hyper-vigilant state of IBS patients and their increased visceral hypersensitivity expose them to an increased risk of developing as well as over-reporting symptoms at very low doses of lactose [18]. This coexistence of lactose intolerance and IBS is the source of symptom exacerbation [11].

\begin{tabular}{|c|c|}
\hline Lactose-containing foods & Lactose content \\
\hline Cow's milk & $5 \mathrm{~g} / 100 \mathrm{~mL}$ \\
\hline Cottage cheese & $1 \mathrm{~g} /$ tablespoon \\
\hline Processed cheese & $1 \mathrm{~g} /$ slice \\
\hline Yogurt & $4 \mathrm{~g} /$ pot \\
\hline Butter & Trace amounts \\
\hline $\begin{array}{l}\text { Cheeses: cheddar, edam, brie, } \\
\text { Danish blue }\end{array}$ & Trace amounts \\
\hline
\end{tabular}

It is necessary to diagnose lactose intolerance in order to discriminate it from other IBS-D [18]. Such diagnosis relies on evaluation of gastro-intestinal symptoms as well as expired hydrogen levels in the breath test with $25 \mathrm{~g}$ of lactose. Treatment is a diet low in lactose with the possibility of oral lactase administration [13]. A trial of lactose avoidance is advised in case of persistent distention despite avoidance of gas-producing foods, but the improvement of symptoms is not equivalent to lactose intolerance [11]. Lactose restriction depends on an individual's tolerance and the severity of their symptoms and generally omits all types of mammalian milk products, like cow, goat, sheep or human milk [9]. A lactose intake smaller than $12 \mathrm{~g}$ during the day showed to produce similar reactions to the placebo, thus GI symptoms caused by smaller doses or a negative breath test may indicate allergy to cow's milk protein in which milk prod- 
ucts from other mammalians are allowed $[9,11,18]$. Exclusion of lactose intolerance is recommended prior to diagnosing IBS. The foods to be avoided on a lactose-free diet are illustrated in Table 3, according to the NICE guidelines [9]. Moreover, special attention is needed for monitoring the calcium status.

\section{Low-FODMAP diet}

One of the most frequently used diets for the management of IBS is the diet low in fermentable oligosaccharides, disaccharides, monosaccharides and polyols (FODMAP) [19]. FODMAPs are a group of short-chain carbohydrates that are poorly absorbed in the small intestine and quickly fermented by gut microbiota [20], which results in symptoms of abdominal distention and discomfort [11]. A low-FODMAP diet involves three phases: restriction, reintroduction and personalization. The first phase, which is followed for six to eight weeks, comprises the elimination of all high-FODMAP foods listed in Table 4 to attain symptom relief. Some patients tend to respond within one to two weeks of the beginning of the diet, while others may take up to four weeks [21]. In the reintroduction phase, the patients are re-exposed to high-FODMAP foods, one type at a time, for a period of two to three days each, to determine the patient's acceptance and tolerance of the type and amount of FODMAP $[20,22]$. Following this, the patient can follow FODMAP personalization during which they consume a less restrictive diet that excludes their personal FODMAP triggers and enables a more diverse dietary intake [23]. Nanayakkara et al. [24] found that $86 \%$ of patients with IBS showed improvement in GI symptoms after following the diet. UpToDate experts suggest a diet low in FODMAPs in patients with IBS who experience the symptoms despite exclusion of gas-producing foods [11]. A 2016 RCT involving 37 individuals who were randomized either to receive twenty-one days of diet low in FODMAPs or a diet high in FODMAPs showed overall better IBS symptom severity scores in subjects on the low-FODMAP diet $(p<0.001)$ [25]. Similar findings were obtained in more recent RCTs [26-28]. Even though many IBS patients tend to benefit from the low-FODMAP diet, Böhn et al. [29] reported comparable efficacy of the low-FODMAP diet and a diet based on traditional dietary advice for IBS (e.g. limiting the intake of fat, caffeine, and alcohol). On the contrary, a meta-analysis by Altobelli et al. [30] found significant reduction in pain and bloating in patients on a low-FODMAP diet as compared to patients on a traditional IBS diet or a high-FODMAP diet. It is important to note that following a low-FODMAP diet might be challenging since it demands the restriction of several food items. For this reason, an experienced specialized dietitian should be counseled to provide a detailed and adequate dietary plan [31].

\section{Diet low in gluten-rich foods}

Gluten avoidance is recommended for patients with celiac disease or non-celiac gluten sensitivity (NCGS) despite conflicting evidence for the latter. NCGS is diagnosed if gluten-related symptoms are present along with absence of both wheat allergy and celiac disease which are ruled out by blood test and endoscopy with biopsy $[9,32]$. Ford et al. [12] states that the gluten-free diet has shown promising effects but further investigation is required in its precise role in IBS and NCGS. Patients with IBS who received a gluten-free diet reported significantly greater improvements in pain, bloating, satisfaction with stool consistency, and tiredness than patients who ingested a diet containing gluten. Chey et al. [3] also reported similar findings. Moreover, gluten appears to induce changes in gut permeability and increase stool frequency in IBS-D patients $[3,11]$. In a recent study by Skodje et al. [33] on non-celiac patients with self-reported sensitivity to gluten and a gluten-free lifestyle, random assignment to gluten, fructan and placebo groups demonstrated significantly higher GI scores of IBS and increased bloating in patients who were receiving fructans compared to gluten. There was no difference in GSRS-IBS scores between the gluten and placebo groups. Fructans are proven responsible for a higher symptomatic risk in patients sensitive to wheat, barley and rye and the coexistence of fructans and gluten in those grains explains the reduced symptomatic IBS control on gluten-free diets [11, 33-35]. Portincasa et al. [13] showed the beneficial role of gluten avoidance due to its association with impaired barrier function of the gut in IBS-D and with the dysfunction of the gut in patients predisposed to celiac disease. Nevertheless, it is important to note that before starting a low-gluten diet, IBS patients should be warned that an inappropriate gluten-free diet may cause nutritional deficiencies as gluten-rich cereals provide valuable source of nutrients [36].

\section{Diet high in fiber}

According to the Codex Alimentarius, dietary fibers are carbohydrate polymers with ten or more monomers that are not hydrolyzed by enzymes in the small intestine [37]. They are classified into two types: soluble, which easily dissolve in water (i.e. the fiber found in oats, barley, peas and beans), and insoluble,

\begin{tabular}{|c|c|c|c|c|c|}
\hline $\begin{array}{l}\text { Fruits/Fruit prod- } \\
\text { ucts }\end{array}$ & $\begin{array}{l}\text { Vegetables/Veg- } \\
\text { etable products }\end{array}$ & Milk products & $\begin{array}{l}\text { Grain/ } \\
\text { /Starch-based foods }\end{array}$ & $\begin{array}{l}\text { Legumes, nuts and } \\
\text { seeds }\end{array}$ & Others \\
\hline $\begin{array}{l}\text { Apple } \\
\text { Apricots } \\
\text { Asian pears } \\
\text { Blackberries } \\
\text { Boysenberry } \\
\text { Cherries } \\
\text { Clingstone } \\
\text { Custard } \\
\text { Mango } \\
\text { Nashi fruit } \\
\text { Nectarines } \\
\text { Peaches } \\
\text { Pears } \\
\text { Plums } \\
\text { Prunes } \\
\text { Persimmon } \\
\text { Tamarillo } \\
\text { Watermelon } \\
\text { White peach }\end{array}$ & $\begin{array}{l}\text { Artichokes } \\
\text { Asparagus } \\
\text { Cauliflower } \\
\text { Garlic } \\
\text { Leek } \\
\text { Mushroom } \\
\text { Onion } \\
\text { Shallot } \\
\text { Snow peas } \\
\text { Spring onion (white } \\
\quad \text { part only) } \\
\text { Sugar snap peas }\end{array}$ & $\begin{array}{l}\text { Cow's milk } \\
\text { Custard } \\
\text { Dairy desserts } \\
\text { Evaporated milk } \\
\text { Goat's milk } \\
\text { Ice cream } \\
\text { Milk powder } \\
\text { Sheep's milk } \\
\text { Sweetened con- } \\
\quad \text { densed milk }\end{array}$ & $\begin{array}{l}\text { Barley-, kamut-, rye-, } \\
\quad \text { and wheat-based } \\
\text { bread } \\
\text { Crackers } \\
\text { Pasta } \\
\text { Cereal } \\
\text { Couscous } \\
\text { Croissants } \\
\text { Crumpets } \\
\text { Gnocchi } \\
\text { Muffins } \\
\text { Noodles }\end{array}$ & $\begin{array}{l}\text { Cashews } \\
\text { Chickpeas } \\
\text { Legumes (i.e. red } \\
\text { kidney beans, } \\
\text { soy beans) } \\
\text { Lentils } \\
\text { Pistachios }\end{array}$ & $\begin{array}{l}\text { Agave } \\
\text { Fructose } \\
\quad \text { Fructo-oligosac- } \\
\text { charides } \\
\text { Fruit juice concen- } \\
\quad \text { trates } \\
\text { High-fructose corn } \\
\quad \text { syrup } \\
\text { Honey } \\
\text { Inulin } \\
\text { Isomalt } \\
\text { Malitol } \\
\text { Polydextrose } \\
\text { Sorbitol }\end{array}$ \\
\hline
\end{tabular}


which stay intact while passing through the intestine (i.e. the fiber found in wheat, rye and other grains). Dietary fibers have a wide range of health benefits, such as reducing the risk of type II diabetes, coronary artery disease, and stroke [11]. Moreover, they have long been used in treating GI disorders, modulating digestion and affecting stool consistency [38]. Over the years, it was widely believed that increasing dietary fibers intake is the ultimate recommendation for patients suffering from IBS. However, literature data reveals that the role of dietary fiber in IBS remains a subject of debate and lacks high-quality evidence [20]. According to UpToDate experts, increasing dietary fiber intake may relieve IBS GI symptoms. Along with dietary intake, fiber supplements, such as psyllium or methylcellulose in particular, could be started at a low dose and increased gradually to reduce any discomfort [11, 39]. A study performed by American College of Gastroenterology (ACOG) assessed the efficacy of therapy in IBS in a series of systematic reviews and found positive effects of soluble fiber and psyllium (only) in overall IBS discomfort and symptoms relief, with weak recommendations and low quality of evidence [12]. Moreover, a systematic review and meta-analysis carried out by Moayyedi et al. [40] on 14 randomized controlled trials (RCTs) including 906 patients with IBS found a significant effect of fiber supplementation in resolving IBS symptoms, as compared to placebo; however, with moderate quality of evidence. Hence, a gradual increase in total daily fiber intake is recommended to reach the target dose of 20-30 grams/day [31].

\section{Individual food components}

\section{Alcohol}

Alcohol consumption has been associated with a wide range of detrimental effects on the immune system, and the liver and gut barrier functions. Literature data have shown inconsistent findings on the effect of alcohol on GI symptoms in IBS patients. On one hand, Reding et al. [41] conducted a prospective study on women aged between 18 and 48 years with or without IBS to investigate the effect of alcohol consumption on Gl symptoms. While moderate to light alcohol consumption was not shown to be associated with GI symptoms in patients with IBS, binge drinking was proven to have the strongest associations with diarrhea $(p=0.006)$, nausea $(p=0.01)$, abdominal pain $(p=0.009)$ and indigestion ( $p=0.004)$ in these individuals. On the other hand, a 2010 cross-sectional survey conducted on individuals with bowel dysfunctions (IBS) and bowel diseases (Crohn's disease and ulcerative colitis) found no difference in the severity of GI symptoms in IBS subjects regardless of the quantity of alcohol consumed [42]. Also, no association was observed between the type of alcoholic beverage and experienced Gl symptoms. Among the reasons of such inconsistent findings is the reliance on subjects' memory and their ability to recall the pattern and effect of alcohol on the severity of their symptoms, which may not be sensitive enough to examine the correlation between alcohol intake and IBS [41]. Nevertheless, IBS patients should be advised to consume alcohol in amounts not exceeding the recommended safe limits, described as no more than one drink for women, and no more than two drinks for men [43]. Whenever the patients feel that alcohol is interfering with their IBS symptoms, they should restrict it [44].

\section{Caffeine}

Caffeine is found in many beverages and products, including coffee, tea, energy drinks, soft drinks, dark chocolate, and some over-the-counter analgesics. It can increase gastric acid secretion, elevate colon motor activity, and trigger rectosigmoid activity, yielding a laxative effect in healthy and susceptible individuals [20, $31,45]$. The role of caffeine in IBS necessitates further research due to the lack of RCTs to determine whether a low caffeine consumption would lead to pain relief in patients with IBS [31]. Nevertheless, Reding et al. [41] found no association between caffeine consumption and IBS symptoms. Therefore, while assessing caffeine intake in IBS patients, daily intake should be restricted to $400 \mathrm{mg}$ (safe limit for adults) if drinking caffeinated beverages is found to be associated with symptom severity [44].

\section{Other food remedies}

There is no clear evidence on the effect of natural therapies on IBS. Some remedies presented by Wald [2] are illustrated in Table 5. Since colonic microflora modification is implicated in the pathophysiology of IBS, the main natural remedies discussed are prebiotics and probiotics. There are also food carriers of probiotics which include fermented yogurts and milk, however, clear evidence on their benefits is missing [9]. Many studies investigated the role of fermented milk containing $B i$ fidobacterium lactis and yogurt strains on GI results. Guyonnet et al. [46] found improved discomfort, decreased bloating and constipation in IBS-C patients who take probiotic milk compared to the control group. There is no counter-indication for the use of fermented prebiotic milk and yogurt other than presence of lactose intolerance, considering that they improve Gl comfort and decrease digestive symptoms even in the healthy population. The ACOG review claims that the quality of evidence on the prebiotic and probiotic effect on IBS is very low and the recommendation is weak [12]. Several systematic reviews and meta-analyses that studied probiotics in IBS patients found a beneficial effect of these organisms in the treatment of IBS [47-49]. However, the RCTs in these meta-analyses are highly heterogeneous, have different study design (size of the study, and duration of the treatment) and use different probiotic species and strains, some of which appear to be more effective than others for specific symptoms $[47,50]$.

\begin{tabular}{|c|c|}
\hline Herb, food or natural remedy & Evidence on efficacy in IBS \\
\hline Peppermint oil & Weak evidence \\
\hline Aloe vera & Lack of evidence \\
\hline Turmeric & Inconclusive \\
\hline Chamomile tea & Unproven \\
\hline Primrose oil & Unproven \\
\hline Fennel seeds & Unproven \\
\hline Wormwood & Unsafe for the nervous system \\
\hline Comfrey & Unsafe for the hepatic system \\
\hline
\end{tabular}

\section{Table 6. Summary of literature on the role of diet in IBS patients}

\begin{tabular}{|l|l|l|}
\hline Type of diet & Findings & References \\
\hline Low in gas-producing foods & $\begin{array}{l}\text { Excluding foods that produce intestinal gas is advised and applicable to all sub- } \\
\text { types of IBS }\end{array}$ & Ref. 9, 11-13, 17, 18 \\
\hline Low in lactose-containing foods & $\begin{array}{l}\text { Avoiding lactose (prior to diagnosis of IBS) is advised in case of persistent dis- } \\
\text { tention despite exclusion of gas-producing foods }\end{array}$ & Ref. 9, 11, 13, 18 \\
\hline Low FODMAP & $\begin{array}{l}\text { A diet low in FODMAP (with the help of a licensed dietitian) is highly recom- } \\
\text { mended in patients with IBS who experience symptoms despite exclusion of } \\
\text { gas-producing foods }\end{array}$ & Ref. 11, 19, 20-29 \\
\hline
\end{tabular}




\begin{tabular}{|c|c|c|}
\hline Type of diet & Findings & References \\
\hline Low in gluten-rich foods & $\begin{array}{l}\text { Fructans (not only gluten) are proven responsible for a higher symptomatic risk } \\
\text { in patients who are sensitive to wheat, barley and rye and who are following } \\
\text { a gluten-free diet }\end{array}$ & $\begin{array}{l}\text { Ref. } 3,9,11-13 \text {, } \\
32-36\end{array}$ \\
\hline High in fiber & $\begin{array}{l}\text { Psyllium (not bran) can be considered in patients with IBS-C. } \\
\text { Nevertheless, the role of dietary fiber in IBS remains a subject of debate and } \\
\text { lacks high quality evidence }\end{array}$ & $\begin{array}{l}\text { Ref. } 11,12,20,31 \\
37-40\end{array}$ \\
\hline Alcohol & $\begin{array}{l}\text { A safe limit for alcohol intake in IBS patients is no more than one drink/d for } \\
\text { women, and no more than two drinks/d for men. } \\
\text { Whenever the patients feel that alcohol is interfering with their IBS symptoms, } \\
\text { they should restrict it }\end{array}$ & Ref. 41-44 \\
\hline Caffeine & $\begin{array}{l}\text { The role of caffeine in IBS is still not clear. } \\
\text { Nevertheless, daily intake should be restricted to } 400 \mathrm{mg} \text { of caffeine if intake is } \\
\text { found to be associated with symptom severity }\end{array}$ & $\begin{array}{l}\text { Ref. } 20,31,41,44, \\
45\end{array}$ \\
\hline Other food remedies & $\begin{array}{l}\text { Probiotics and prebiotics may improve symptoms in IBS patients; however, the } \\
\text { quality of evidence is very low and the recommendation is weak }\end{array}$ & Ref. $2,9,12,46-50$ \\
\hline
\end{tabular}

\section{Conclusions}

IBS is considered one of the functional disorders that might interfere with an individual's quality of life. However, it neither shortens the expected life span nor leads to cancer of the bowel, blockage of the gut, or other serious conditions. Stress management such as practicing relaxation techniques, exercising regularly and getting adequate sleep is an important part of the treatment for IBS. Yet, the component that contributes greatly to the aggravation or alleviation of IBS symptoms is the dietary habits. Even though further larger RCTs are needed for clearer and more conclusive findings, the evidence to date indicates that out of the different types of diets mentioned above, short-term restriction of FODMAP may be the most effective dietary intervention for reducing IBS symptoms. Nonetheless, it is important to have proper follow-up by a health-care practitioner and a licensed dietitian in order to specify the appropriate food triggers to be eliminated, while maintaining an adequate nutritional status.

Source of funding: This work was funded from the authors' own resources.

Conflicts of interest: The authors declare no conflicts of interest.

\section{References}

1. Mearin F, Lacy BE, Chang L, et al. Bowel disorders. Gastroenterology 2016; 150(6): 1393-1407.

2. Wald A. Clinical manifestations and diagnosis of irritable bowel syndrome in adults. UpToDate. 2019 [cited 1.12.2020]. Available from URL: https://www.uptodate.com/contents/clinical-manifestations-and-diagnosis-of-irritable-bowel-syndrome-in-adults?topicRef=2631\& source=see_link\#H2263560866.

3. Chey WD, Kurlander J, Eswaran S. Irritable Bowel Syndrome a clinical review. JAMA 2015; 313: 949-958.

4. Sperber AD, Dumitrascu D, Fukudo S, et al. The global prevalence of IBS in adults remains elusive due to the heterogeneity of studies: a Rome Foundation working team literature review. Gut 2017; 66(6): 1075-1082.

5. Zannini E, Arendt EK. Low FODMAPs and gluten-free foods for irritable bowel syndrome treatment: lights and shadows. Food Res Int 2018; 110: 33-41.

6. Asha MZ, Khalil SFH. Efficacy and safety of probiotics, prebiotics and synbiotics in the treatment of Irritable Bowel Syndrome: a systematic review and meta-analysis. Sultan Qaboos Univ Med J 2020; 20(1): e13-e24.

7. Ireton-Jones C, Weisberg MF. Management of Irritable Bowel Syndrome: physician-dietitian collaboration. NCP 2020; 35(5), doi: 10.1002/ncp.10567.

8. Fadgyas-Stanculete M, Dumitrascu DL, Pojoga C, et al. Coping strategies and dysfunctional cognitions as predictors of irritable bowel syndrome diagnosis. JCBPR 2015; 15(1): 111.

9. Clinical practice guideline irritable bowel syndrome in adults: diagnosis and management of irritable bowel syndrome in primary care National Collaborating Centre for Nursing and Supportive Care commissioned by National Institute for Health and Clinical Excellence. 2008 Feb. [cited 15.12.2020]. Available from URL: https://www.nice.org.uk/guidance/cg61/evidence/full-guidance-pdf-196701661.

10. Chumpitazi BP, Self MM, Czyzewski DI, et al. Bristol Stool Form Scale reliability and agreement decreases when determining Rome III Stool Form Designations. Neurogastroenterol Motil 2016; 28(3): 443-448.

11. Wald A. Treatment of irritable bowel syndrome in adults. UpToDate. 2020 [cited 15.12.2020]. Available from URL: https://www.uptodate.com/contents/treatment-of-irritable-bowel-syndrome-in-adults.

12. Ford AC, Moayyedi P, Lacy BE, et al. American College of Gastroenterology monograph on the management of irritable bowel syndrome and chronic idiopathic constipation. Am J Gastroenterol 2014; 109(S1): S2.

13. Portincasa P, Bonfrate L, de Bari O, et al. Irritable bowel syndrome and diet. Gastroenterol Rep (Oxf) 2017; 5(1): 11-19.

14. Irritable bowel syndrome: diagnosis and management. Minerva Gastroenterologica e Dietologica 2020; 66(2): 136-150.

15. Canakis A, Haroon M, Weber HC. Irritable bowel syndrome and gut microbiota. Curr Opin Endocrinol Diabetes Obes 2020; 27(1): 28-35.

16. Pimentel M, Lembo A. Microbiome and its role in Irritable Bowel Syndrome. Dig Dis Sci 2020; 65(3): 829-839.

17. Major G, Pritchard S, Murray K, et al. Colon hypersensitivity to distension, rather than excessive gas production, produces carbohydrate-related symptoms in individuals with Irritable Bowel Syndrome. Gastroenterology 2017; 152(1): 124-133.

18. Yang J, Deng $\mathrm{Y}, \mathrm{Chu} \mathrm{H}$, et al. Prevalence and presentation of lactose intolerance and effects on dairy product intake in healthy subjects and patients with Irritable Bowel Syndrome. Clin Gastroenterol Hepatol 2013; 11(3): 262-268.

19. Liu J, Chey WD, Haller E, et al. Low-FODMAP diet for Irritable Bowel Syndrome: what we know and what we have yet to learn. Annu Rev of Med 2020; 71: 303-314. 
20. Singh R, Salem A, Nanavati J, et al. The role of diet in the treatment of irritable bowel syndrome: a systematic review. Gastroenterol Clin North Am 2018; 47(1): 107-137.

21. Chey WD. Food: the main course to wellness and illness in patients with Irritable Bowel Syndrome. Am J Gastroenterol 2016; 111(3): 366-371.

22. Dugum M, Barco K, Garg S. Managing irritable bowel syndrome: the low-FODMAP diet. Cleve Clin J Med 2016; 83(9): 655-662.

23. Whelan K, Martin LD, Staudacher HM, et al. The low FODMAP diet in the management of irritable bowel syndrome: an evidence-based review of FODMAP restriction, reintroduction and personalisation in clinical practice. J Hum Nutr Diet 2018; 31(2): $239-255$.

24. Nanayakkara WS, Skidmore PM, O'Brien L, et al. Efficacy of the low FODMAP diet for treating irritable bowel syndrome: the evidence to date. Clin Exp Gastroenterol 2016; 9: 131-142.

25. McIntosh K, Reed DE, Schneider T, et al. FODMAPs alter symptoms and the metabolome of patients with IBS: a randomised controlled trial. Gut 2016; 66(7): 1241-1251.

26. Eswaran SL, Chey WD, Han-Markey T, et al. A randomized controlled trial comparing the low FODMAP diet vs. modified NICE guidelines in US adults with IBS-D. Am J Gastroenterol 2016; 111(12): 1824.

27. Gravina AG, Dallio M, Romeo M, et al. Adherence and effects derived from FODMAP diet on Irritable Bowel Syndrome: a real life evaluation of a large follow-up observation. Nutrients 2020; 12(4): 928.

28. Clevers E, Tran M, Van Oudenhove L, et al. Adherence to diet low in fermentable carbohydrates and traditional diet for irritable bowel syndrome. Nutrition 2020; 73: 110719.

29. Böhn L, Störsrud S, Liljebo T, et al. Diet low in FODMAPs reduces symptoms of irritable bowel syndrome as well as traditional dietary advice: a randomized controlled trial. Gastroenterology 2015; 149(6): 1399-1407.

30. Altobelli E, Del Negro V, Angeletti PM, et al. Low-FODMAP diet improves irritable bowel syndrome symptoms: a meta-analysis. Nutrients 2017; 9(9): 940.

31. Cozma-Petruţ A, Loghin F, Miere D, et al. Diet in irritable bowel syndrome: what to recommend, not what to forbid to patients! World J Gastroenterol 2017; 23(21): 3771.

32. Barone M, Gemello E, Viggiani MT, et al. Evaluation of non-celiac gluten sensitivity in patients with previous diagnosis of Irritable Bowel Syndrome: a randomized double-blind placebo-controlled crossover trial. Nutrients 2020; 12(3): 705.

33. Skodje G, Sarna V, Minelle I, et al. Fructan, rather than gluten, induces symptoms in patients with self-reported non-celiac gluten sensitivity. Gastroenterology 2018; 154(3): 529-539.

34. Biesiekierski JR, Iven J. Non-coeliac gluten sensitivity: piecing the puzzle together. United European Gastroenterol J 2015; 3(2): 160-165.

35. Makharia A, Catassi C, Makharia GK. The overlap between irritable bowel syndrome and non-celiac gluten sensitivity: a clinical dilemma. Nutrients 2015; 7(12): 10417-10426.

36. Volta U, Pinto-Sanchez MI, Boschetti E, et al. Dietary triggers in irritable bowel syndrome: is there a role for gluten? J Neurogastroenterol Motil 2016; 22(4): 547-557.

37. Yan YL, Hu Y, Gänzle MG. Prebiotics, FODMAPs and dietary fiber-conflicting concepts in development of functional food products? COFS 2018; 20: 30-37.

38. El-Salhy M, Ystad SO, Mazzawi T, et al. Dietary fiber in irritable bowel syndrome (review). Int J Mol Med 2017; 40(3): 607-613.

39. McRorie JW. Evidence-based approach to fiber supplements and clinically meaningful health benefits, Part 2. Nutr Today 2015; 50(2): 90-97.

40. Moayyedi P, Quigley EM, Lacy B, et al. The effect of fiber supplementation on irritable bowel syndrome: a systematic review and metaanalysis. Am J Gastroenterol 2014; 109(9): 1367-1374.

41. Reding KW, Cain KC, Jarrett ME, et al. Relationship between patterns of alcohol consumption and gastrointestinal symptoms among patients with irritable bowel syndrome. Am J Gastroenterol 2013; 108(2): 270-276.

42. Swanson GR, Sedghi S, Farhadi A, et al. Pattern of alcohol consumption and its effect on gastrointestinal symptoms in inflammatory bowel disease. Alcohol 2010; 44(3): 223-228.

43. U.S. Department of Health and Human Services and U.S. Department of Agriculture. Dietary Guidelines for Americans. $8^{\text {th }}$ Edition. 2015. Available from URL: https://health.gov/sites/default/files/2019-09/2015-2020_Dietary_Guidelines.pdf.

44. McKenzie YA, Bowyer RK, Leach $\mathrm{H}$ et al. British Dietetic Association systematic review and evidence-based practice guidelines for the dietary management of irritable bowel syndrome in adults (2016 update). J Hum Nutr Diet 2016; 29(5): 549-575.

45. Capili B, Anastasi JK, Chang M. Addressing the role of food in Irritable Bowel Syndrome symptom management. J Nurse Pract 2016; 12(5): 324-329.

46. Guyonnet D, Chassany O, Ducrotte P, et al. Effect of a fermented milk containing Bifidobacterium animalis DN-173 010 on the healthrelated quality of life and symptoms in irritable bowel syndrome in adults in primary care: a multicentre, randomized, double-blind, controlled trial. Aliment Pharmacol Ther 2007; 26: 475-486.

47. Zhang Y, Li L, Guo C, et al. Effects of probiotic type, dose and treatment duration on irritable bowel syndrome diagnosed by Rome III criteria: a meta-analysis. BMC Gastroenterol 2016; 16(1): 62.

48. Lackner JM, Jaccard J, Keefer L, et al. Improvement in gastrointestinal symptoms after cognitive behavior therapy for refractory Irritable Bowel Syndrome. Gastroenterology 2018; 155(1): 47-57.

49. Gendi R, Jahan N. Pharmacological and non-pharmacological treatments of Irritable Bowel Syndrome and their impact on the quality of life: a literature review. Cureus 2020; 12(7): e9324.

50. Lacy BE, Chey WD, Lembo AJ. New and emerging treatment options for Irritable Bowel Syndrome. Gastroenterol Hepatol (NY) 2015; 11: 1-19.

Tables: 6

Figures: 1

References: 50

Received: 05.02.2021

Reviewed: 23.02 .2021

Accepted: 18.05 .2021
Address for correspondence:

Antoine Aoun, MD, PhD

Medical Center (Office of Student Affairs)

Faculty of Nursing and Health Sciences

Notre Dame University-Louaize

P.O. Box: 72 Zouk Mikael

Zouk Mosbeh

Lebanon/Liban

Tel.: +961 9218950 (ext. 5056)

E-mail: aaoun@ndu.edu.lb 